\title{
The Future of Amorphous Silicon Photovoltaic Technology
}

R. Crandall, W. Luft

Submitted to

Progress in Photovoltaics

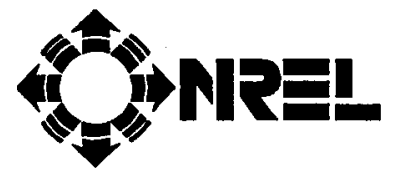

National Renewable Energy Laboratory 1617 Cole Boulevard

Golden, Colorado 80401-3393

A national laboratory of the U.S. Department of Energy Managed by Midwest Research Institute for the U.S. Department of Energy under contract No. DE-AC36-83CH10093

Prepared under Task No. PV531101

June 1995 


\section{NOTICE}

This report was prepared as an account of work sponsored by an agency of the United States government. Neither the United States government nor any agency thereof, nor any of their employees, makes any warranty, express or implied, or assumes any legal liability or responsibility for the accuracy, completeness, or usefulness of any information, apparatus, product, or process disclosed, or represents that its use would not infringe privately owned rights. Reference herein to any specific commercial product, process, or senvice by trade name, trademark, manufacturer, or otherwise does not necessarily constitute or imply its endorsement, recommendation, or favoring by the United States government or any agency thereof. The views and opinions of authors expressed herein do not necessarily state or reflect those of the United States government or any agency thereof.

Available to DOE and DOE contractors from:

Office of Scientific and Technical Information (OSTI)

P.O. Box 62

Oak Ridge, TN 37831

Prices available by calling (615) $576-8401$

Available to the public from:

National Technical Information Service (NTIS)

U.S. Department of Commerce

5285 Port Royal Road

Springfield, VA 22161

(703) $487-4650$ 


\title{
THE FUTURE OF AMORPHOUS SILICON PHOTOVOLTAIC TECHNOLOGY
}

\author{
R. Crandall and W. Luft \\ National Renewable Energy Laboratory \\ Golden, CO 80401, USA
}

\begin{abstract}
Amorphous silicon modules are commercially available. They are the first truly commercial thin-film photovoltaic (PV) devices. Well-defined production processes over very large areas $\left(>1 \mathrm{~m}^{2}\right)$ have been implemented. There are few environmental issues during manufacturing, deployment in the field, or with the eventual disposal of the modules. Manufacturing safety issues are well characterized and controllable. The highest measured initial efficiency to date is $13.7 \%$ for a small triple-stacked cell and the highest stabilized module efficiency is $10 \%$. There is a consensus among researchers, that in order to achieve a $15 \%$ stabilized efficiency, a triple-junction amorphous silicon structure is required. Fundamental improvements in alloys are needed for higher efficiencies. This is being pursued through the DOE/NREL Thin-Film Partnership Program. Cost reductions through improved manufacturing processes are being pursued under the National Renewable Energy Laboratory/U.S. Department of Energy (NREL/DOE)-sponsored research in manufacturing technology (PVMaT). Much of the work in designing a-Si devices is a result of trying to compensate for the StaeblerWronski effect. Some new deposition techniques hold promise because they have produced materials with lower stabilized defect densities. However, none has yet produced a high efficiency device and shown it to be more stable than those from standard glow discharge deposited material.
\end{abstract}

\section{INTRODUCTION}

Amorphous silicon modules are commercially available. They are the first truly commercial thin-film photovoltaic (PV) devices. However, like other pioneering technologies, amorphous silicon (a-Si) is not without its problems: conversion efficiencies of present commercial modules are low (near 5\%). The low efficiency is partially attributable to the tendency of amorphous silicon devices to degrade by some amount under illumination, after which they are essentially stabilized. This degradation (called the Staebler-Wronski Effect) is being addressed by fundamental investigations and is being mitigated by design approaches.

Due to these problems, amorphous silicon has not yet had a "breakthrough" impact on PV sales. Worldwide, a-Si devices accounted for $16 \%$ of all PV sales in 1994 in terms of power output. ${ }^{1}$ It is believed that a $15 \%$ stabilized module efficiency must be reached for a-Si to become cost-competitive with fossil-fuel based electricity and in the long run to be competitive with other PV technologies . [Economic aspects are covered by $\mathrm{K}$. Zweibel in this issue]. 
Thin-film PV technologies, such as amorphous silicon, hold the promise for low cost. $^{2}$ Of the thin-film technologies, amorphous silicon is the most mature. Other thinfilm technologies have promise, but their manufacturing process yields and costs have not yet been proven. It might take some time to do so. It has taken $\mathrm{PV} \mathrm{a-Si} \mathrm{about} 10$ years to build up to the present manufacturing capacity. Amorphous silicon has a reasonable probability of being the first thin-film technology to achieve the U.S. DOE intermediate cost goal of $\$ 100 / \mathrm{m}^{2}$.

Amorphous silicon deposition has a good tolerance to process control variables, which is helpful in manufacturing as it facilitates equipment design and process control. Versatile processing on glass, stainless steel, or polymers and automated, continuous-flow processing for high-volume production has been demonstrated. Well-defined production processes over very large areas $\left(>1 \mathrm{~m}^{2}\right)$ have been implemented. The module design can be monolithic, which means that patterning and cell interconnections are part of the fabrication process. This leads to reduced module costs. An industrial base exists for large-area processing for photovoltaic and non-photovoltaic amorphous silicon applications, both of which have similar production requirements. There are few environmental issues during manufacturing, deployment in the field, or with the eventual disposal of the modules. Manufacturing safety issues are well characterized and controllable.

\section{PRESENT STATUS}

This section describes the present status of a-Si device design, prototype module performance, deposition methods used by industry and in research, manufacturing activities by the a-Si PV industry, and the a-Si PV market.

\section{Device Design}

The device design includes such matters as single-junctions or multijunctions, the type of conducting electrodes, back reflector material and texture, substrate or superstrate deposition and materials, and selection of bandgaps and thicknesses for the various layers.

\section{Single-Junction Devices}

The first reasonable efficiency amorphous silicon solar cells were $p-i-n$ junction devices. In these devices the $p$ - and $n$-type doped layers are made thin and the absorber layer is the intrinsic layer. Because of the low photocarrier ambipolar-diffusion length, efficient solar cells require separation of electrons and holes by the electric field in the absorber layer. This limits the thickness of the absorber to under $0.5 \mu \mathrm{m}$. The majority of device makers deposit the $p$ layer, doped with boron, on a glass substrate that is coated with a conducting transparent oxide (CTO). To increase the light transmission of the $p$ layer, a-Si:H is alloyed with carbon that increases the bandgap. The $n$-type layer is doped with phosphorous. This type of structure, shown in Fig. 1(a), is referred to as a superstrate device. Although this structure is the easiest to fabricate, it has shortcomings that limit its efficiency. The foremost is that the absorber layer is too thin to absorb much of the solar spectrum beyond $650 \mathrm{~nm}$. Using a thicker absorber layer reduces the efficiency 
because of poor photocarrier collection.

The simplest method to increase the amount of absorbed light is to make a lighttrapping structure producing multiple internal reflections in the absorber layer. ${ }^{3}$ The superstrate structure, the most common configuration, begins with transparent conducting tin oxide-coated glass either supplied by the glass manufacturer or coated by the device fabricator. This coating, which is textured on the scale of the absorbed light, dictates the success of the light-trapping structure. The rough tin oxide refracts light passing through the structure, effectively increasing the optical path in the amorphous silicon. A welldesigned structure can increase the optical path more than twofold. ${ }^{4}$ Since the CTO dictates the growth of subsequent layers in the device, its morphology is a compromise between an extremely rough surface, that might give the best light trapping, and a smoother surface that produces pin-hole-free growth of the $p$ layer. This pin-hole-free growth is important as pin holes can produce shunts in the devices. ${ }^{5}$ These shunts occur because the pin-hole region permits contact of the $i$ layer to the $n$ type CTO. In this situation, the normal $p$ layer barrier is absent causing an increase in the dark current. The electrical contact to the $n$ layer is chosen to give the highest reflectivity. A zinc oxide/silver composite layer is often used to give high reflectivity and increased life.

A variation of the above structure, the substrate device, is achieved by depositing the $n$ layer first. ${ }^{6} \quad$ The substrate structure Fig. 1(b) achieves its light-trapping ability through the silver/CTO layer deposited on the conducting substrate, usually stainless steel. As in the case of the superstrate structure, this surface determines the growth of subsequent junction layers. The silver/CTO contact is used as an example as other materials may work as well. The choice of reflecting materials is dictated by ease of deposition, high reflectivity, and longevity. The transparent top contact, indium tin oxide, to the device is chosen for its high conductivity and low optical absorption. This structure permits a microcrystalline $p$-type top contact that gives a high open-circuit voltage. ${ }^{7}$ The substrate design requires no front cover glass. As the glass represents a major cost item, this is a distinct advantage.

\section{Multijunction Devices}

To circumvent the limitations imposed by the single-junction devices, researchers use multijunction devices containing as many as three different absorber layers with differing bandgaps. In the earliest versions, multijunction a-Si cells were used (without altering bandgaps) merely to absorb more light. However, to take advantage of the potential of multijunctions for higher efficiency, researchers sought to develop different bandgap materials to incorporate in the multijunction design. Two materials evolved: a higher bandgap alloy made with carbon; and a lower bandgap alloy made with germanium. Today, the mainstream device design for high efficiency cells is based on multijunctions using one or more of these alloys to supplement an a-Si cell, in either a two- or threejunction design. Such a structure provides an important avenue for future improvements. A typical triple-junction stack is shown in Figure 2. Typically, the first absorber is alloyed with carbon to increase the bandgap above the $1.75 \mathrm{eV}$ gap of a-Si:H, the second absorber is a-Si:H, and the third absorber is alloyed with germanium to reduce the bandgap. Other alloys have been tried but with far from encouraging results. A multijunction device, irrespective of the material used, is the best way to approach the ultimate PV efficiency 
dictated by the laws of thermodynamics. ${ }^{8}$ These considerations lead to maximum theoretical efficiencies of $22 \%$ for a $1.7 \mathrm{eV}$ single-gap cell, $29 \%$ for a $1.95 \mathrm{eV} / 1.4 \mathrm{eV}$ dual tandem cell, and 33\% for a 2.1/1.7/1.25 eV triple tandem cell. Predictions based on computer models ${ }^{9}$ give an ultimate efficiency of $21 \%$ for a dual-stacked structure with $1.75 \mathrm{eV} / 1.15 \mathrm{eV}$ bandgaps and $24 \%$ for a triple-stacked cell with $2.0 \mathrm{eV} / 1.7 \mathrm{eV} / 1.45 \mathrm{eV}$ bandgaps. In practice these efficiency values will be hard to achieve because of reflection and absorption losses and recombination of photogenerated carriers. A more realistic upper limit to the triple-stacked cell efficiency may be about $18 \% .^{2}$ The highest measured initial active-area efficiency to date is $13.7 \%$ for a small triple-stacked cell. ${ }^{6}$

There is a consensus among researchers, that in order to achieve a $15 \%$ stabilized efficiency, a triple-junction amorphous silicon structure is required. Consequently, major efforts have been directed toward such a structure.

\section{Superstrate vs. substrate}

Both the superstrate and substrate designs have their particular advantages. Devices using the superstrate configuration have to date reported lower initial efficiencies in the range $10-12 \%$ while the substrate design has resulted in the highest initial active-area efficiency of $13.7 \%$. The substrate device structure is so far the only one to achieve a stabilized module efficiency above $10 \% .^{10}$

The $p$ layer in the substrate device can be made microcrystalline thereby giving high conductivity and increased transparency compared with an amorphous $p$ layer. The superstrate device requires a thick transparent front contact to achieve both the lighttrapping structure and low electric series resistance. This results in a significant light loss. To date, no one has been successful in depositing a thin microcrystalline $p$ layer on this front contact.

The superstrate design is somewhat easier to manufacture in large-area modules because of the ease of monolithic interconnections, whereas the substrate presents difficulty connecting different submodules together in a monolithic panel. Development to overcome this difficulty is presently under way.

\section{Performance}

In 1982, only one research group reported initial cell efficiencies greater than $10 \%$. In 1989, 25 research groups reported initial cell efficiencies greater than 10\%. The best present prototype a-Si module performance data for products from several companies and for several module types are shown in Table 1 . All stabilized efficiencies in this paper refer to devices subjected to $>600$ hours of 1 sun illumination at $50^{\circ} \mathrm{C}$. 
Table 1. Best amorphous silicon module stabilized efficiencies (measured at NREL with a solar simulator after 600-2000 hours of light soaking except where indicated).

\begin{tabular}{|c|c|c|c|c|}
\hline Manufacturer & Module Type & $\begin{array}{l}\text { Area } \\
\left(\mathrm{cm}^{2}\right)\end{array}$ & $\begin{array}{c}\text { Power } \\
\text { (W) }\end{array}$ & $\begin{array}{l}\text { Efficiency } \\
(\%)\end{array}$ \\
\hline \multirow[t]{3}{*}{ Solarex } & $\mathrm{Si} / \mathrm{SiGe}$ & 842 & 7.7 & $9.1 \S$ \\
\hline & $\mathrm{Si} / \mathrm{SiGe}$ & 3,432 & 26.9 & $7.8 \S \dagger$ \\
\hline & $\mathrm{Si} / \mathrm{Si} / \mathrm{SiGe}$ & 863 & 7.6 & $8.8 \dagger$ \\
\hline \multirow{3}{*}{$\begin{array}{l}\text { United Solar } \\
\text { Systems } \\
\text { Corporation }\end{array}$} & $\mathrm{Si} / \mathrm{Si}$ & 3,676 & 22.8 & $6.2 \ddagger$ \\
\hline & $\mathrm{Si} / \mathrm{SiGe}$ & 902 & 8.6 & $9.5 \dagger$ \\
\hline & $\mathrm{Si} / \mathrm{Si} / \mathrm{SiGe}$ & 903 & 9.2 & $10.2 \S$ \\
\hline $\mathrm{ECD}$ & $\mathrm{Si} / \mathrm{Si} / \mathrm{SiGe}$ & 3,906 & 30.6 & 7.8 \\
\hline Fuji & $\mathrm{Si} / \mathrm{Si}$ & 1,200 & 10.7 & 8.9 \\
\hline \multirow{3}{*}{$\begin{array}{l}\text { Advanced } \\
\text { Photovoltaic } \\
\text { Systems } \\
\text { Corporation }\end{array}$} & $\mathrm{Si}$ & 11,634 & 51.2 & $4.4 \ddagger$ \\
\hline & $\mathrm{Si} / \mathrm{Si}$ & 848 & 6.0 & $7.1 \dagger$ \\
\hline & $\mathrm{Si} / \mathrm{Si}$ & 11,522 & 53.0 & $4.6 \ddagger$ \\
\hline
\end{tabular}

$\dagger$ Not verified by NREL measurements, $\ddagger$ Outdoor exposure and measurement $\S$ Not light-soaked at NREL

\section{Deposition Methods}

Several methods have been used to deposit amorphous silicon from silane or other silicon carrier gases. These include: chemical vapor deposition (CVD), direct current (dc) and radio-frequency (rf) glow discharge (plasma-enhanced chemical vapor deposition), microwave glow discharge, electron-cyclotron-resonance (ECR) glow discharge, remoteplasma-assisted CVD, controlled plasma magnetron (CPM) glow discharge, photolytic decomposition (photo-CVD), sputtering, cluster beam evaporation, and hot-wire decomposition. Of these, rf and dc glow-discharge depositions are the most common and are those used by industry. Glow discharge has demonstrated ease of scale-up and excellent uniformity over square-meter areas. In addition, it has produced the highest efficiency solar cells and modules. Some of the newer techniques, such as, ECR, remoteplasma-assisted CVD, and hot-wire deposition, have produced materials with intriguing properties, such as, lower defect density and greater diffusion length. They may hold promise for the future.

Of the non-plasma CVD methods, only photo-CVD has resulted in devices comparable to glow-discharge deposited devices. It was hoped that this method would result in materials more resistant to the Staebler-Wronski effect. However, these hopes were soon dashed, because the material and devices degrade similarly to glow-discharge deposited material. In addition, there are serious drawbacks to its use on an industrial 
scale. The most notables are the loss of film uniformity upon scale-up because the deposition rate depends on the light intensity and film deposition on the window, gradually reducing the light entering the deposition chamber.

To make the optimum material, one must explore a large parameter space determined by gas composition, flow rate, pressure, temperature, substrate temperature, and reactor design. The optimum a-Si: $\mathrm{H}$ material has traditionally been produced at a substrate temperature of around $250^{\circ} \mathrm{C}$ and contains about 10 at.\% H. However, the optimum parameter space is constantly being expanded as new insights are obtained. For example, some gas mixtures used to deposit a-Si:H contain $\mathrm{SiH}_{4}, \mathrm{Si}_{2} \mathrm{H}_{6}, \mathrm{SiF}_{4}$, and $\mathrm{H}_{2}$ while others may use only $\mathrm{SiH}_{4}$. The most recent route to obtain higher quality films is to use H-dilution of the feedstock gases. This improves the initial film quality in some systems and leads to less light-induced degradation in solar cells. To decrease the bandgap, mixtures of silane and germane with or without disilane and hydrogen are typically used to make a-Si:Ge:H alloy. Methane and silane are the most common mixtures to produce a-Si:C:H alloy. Phosphine and silane mixtures are the best for the $n$ layer, whereas diborane, boron trifluoride or trimethylboron produce a $p$-type dopant. Because the limited shelf-life of diborane can cause reproducibility problems in manufacturing, trimethylboron or $\mathrm{BF}_{3}$ are finding increased use.

\section{Manufacturing}

There is an emerging a-Si photovoltaic industry. In the U.S., several companies have been developing the a-Si technology. The key ones are: United Solar Systems Corporation, Energy Conversion Devices, Inc. (ECD), Solarex, Advanced Photovoltaic Systems, Inc. (APS), Utility Power Group, and Iowa Thin Film Technologies.

Amorphous silicon PV has various strengths: (1) substantial investment in scale-up and manufacturing has resolved many manufacturing-related issues, allowing for greater confidence that laboratory progress will translate into commercial modules; (2) silicon materials are abundant and are not regarded as environmentally dangerous (at the product level); and (3) substantial knowledge of amorphous silicon is being developed outside of photovoltaics for non-photovoltaics a-Si applications, such as, thin-film transistors. ${ }^{2}$ The a-Si technology has been well adapted to manufacturing. Scale-up from laboratory cells to full-sized modules results only in a $0.02-0.05$ reduction in total-area conversion efficiency. Module sizes range from 0.1 to $>1 \mathrm{~m}^{2}$. However, the advent of multijunction devices raises new manufacturing issues for a-Si: multiple, very thin layers are a challenge to even a manufacturing-friendly technology. Unfortunately, the triple-junction structure introduces manufacturing complexities and increases cost. True understanding of these issues awaits more substantial a-Si manufacturing volume. Current thinking suggests that ease of manufacturing of thin layers is not by itself a particularly serious challenge. Rather, potential shunting is a problem, mainly because of textured $\mathrm{ZnO}$ or $\mathrm{SnO}_{2}$ used for light trapping at the bottom of device structures.

A key component of an economical manufacturing process is a high throughput. Laboratory deposition systems usually make one device at a time. Manufacturers use a variety of methods to achieve high throughput. APS uses a batch process with a large reactor containing many glass substrates for a number of large glass modules. This process is labor intensive at the moment. Solarex uses a continuous automated process 
to continuously produce encapsulated modules without manual handling. ${ }^{2}$ United Solar and ECD use a continuous roll-to-roll deposition on stainless steel substrates ${ }^{11}$, and Iowa Thin Films Technologies uses a continuous roll-to-roll deposition on plastic. ${ }^{12} \mathrm{~A}$ high deposition rate is also necessary for an economical manufacturing process. The best glow discharge material is produced at a deposition rate between 0.1 and $0.2 \mathrm{~nm} / \mathrm{s}$. Since most device absorber layers are about $500 \mathrm{~nm}$ thick, it takes up to an hour to grow the $i$ layer. In manufacturing, a compromise between high growth rate and film quality is made. For any given deposition process, the film quality deteriorates as the deposition rate is increased. ${ }^{13}$ Microwave glow discharge has demonstrated high quality SiGe devices grown at rates as high as $10 \mathrm{~nm} / \mathrm{s}^{14}$

Cost reductions through improved manufacturing processes are being pursued under the National Renewable Energy Laboratory/U.S. Department of Energy (NREL/DOE)-sponsored research in manufacturing technology (PVMaT). Under this project, Energy Conversion Devices, Inc. has demonstrated 8\% stabilized efficiency for a $0.37 \mathrm{~m}^{2}$ triple-junction a-Si module, high (99.7\%) subcell yields, and substantial (56\%) material cost reductions. Solarex has reduced area losses caused by laser interconnections by $50 \%$ and demonstrated high uniformity of film thicknesses $( \pm 3 \%)$ over $0.74 \mathrm{~m}^{2}$ areas, as well as substantial material cost reductions. Advanced Photovoltaic Systems has also demonstrated significant cost reductions by reduced processing time..$^{15}$

The emerging a-Si PV industry has achieved a momentum in terms of production and market share both in the United States and worldwide. In 1982, Sanyo established the first MW/year-capacity production plant. In 1984, the first 1-MW/year-capacity production plant in the U.S. was established by the Chronar Corporation in Port Jervis, New Jersey. A 10-MW/yr-capacity plant has been built by APS in Fairfield, California in 1993 and another 10-MW/yr-capacity plant is being built by United Solar in Newport News, Virginia. Amoco/Enron Solar, a recent joint venture, is planning a $10-\mathrm{MW} / \mathrm{yr}$ facility (using the Solarex thin-film technology) to be completed by 1996. Four U.S. companies have presently commercial a-Si products.

\section{Market}

In 1982, 1.5 $\mathrm{MW}_{\mathrm{p}}$ amorphous silicon was produced for consumer products, representing a 13\% share of the world PV market. The peak market share of 39\% (13.9 MW) for a-Si was reached in 1988. In 1994, approximately $11 \mathrm{MW}_{\mathrm{p}}$ amorphous silicon was produced world-wide; 6.6 MW for indoor applications (calculators, watches, etc.) and 4.2 MW for terrestrial applications. U.S. electric utilities are showing a commitment to the a-Si technology by establishing outdoor test beds for photovoltaics. The largest one is a 400 $\mathrm{kW}_{\mathrm{p}}$ system by Photovoltaic Utility-Scale Applications (PVUSA) in California using Advanced Photovoltaic Systems single-junction a-Si modules. 


\section{RESEAKLH DIREL"IIUNS}

Issues that affect the future of the a-Si technology are the following:

1. Low Device Efficiencies

2. The Staebler-Wronski Effect

3. Manufacturability of innovations that are designed to affect issues 1 and 2 .

The appeal of amorphous silicon is its ease of manufacturing and its potential for low cost. Nevertheless, it suffers from low efficiency compared to crystalline photovoltaics. Much effort has gone into improving the device efficiency. The early work was devoted to higher efficiency cells and resulted in obtaining the record for a triple-stacked cell of $13.7 \%$ initial efficiency. Now, most of the effort goes into translating this high value into better module efficiency. However, there is still an effort by various research groups to develop new materials and innovations to improve cell efficiency. Both of these efforts are being pursued under the National Renewable Energy Laboratory/U.S. Department of Energy (NREL/DOE)-sponsored Thin-Film Partnership Program.

These issues all revolve around the 'Achilles Heel' of amorphous silicon, the lightinduced degradation. This effect is unique to a-Si, and is due to its amorphous structure. No other thin-film photovoltaic material displays the same problem. Until a few years ago, it was feared that the Staebler-Wronski Effect (SWE) would gradually reduce a-Si device efficiencies to zero. However, it was found that a competing effect, thermal annealing during normal outdoor operation, tended to counter the degradation. This allows a steady state to be reached after lengthy exposure, with the losses held to about $15 \%$ to $30 \%$. Procedures are being developed to standardize measurements of this reduction of the stabilized performance. However, there are as yet no fully accepted methods. The current approach is to expose modules to sunlight (or simulated sunlight) for about 1000 hours at $50^{\circ} \mathrm{C}$. This is believed to account for over $95 \%$ of the overall expected degradation. As a countermeasure against the problem of SWE degradation, a-Si companies have developed an excellent warranty strategy: they warrant the output of modules for $10-12$ years at some fraction $(80 \%-90 \%)$ of the nameplate rating. This assures the buyer that they will receive a known minimum power output.

Improvements in the initial efficiency now correlate well with improvements in the stabilized efficiency. This was not always the case, because earlier increased performance was achieved by increasing the thickness of the absorber layer and this increased the degradation. Below we describe various approaches in terms of improvements in open-circuit voltage, $\mathrm{V}_{\mathrm{oc}}$; fill factor, FF; and short-circuit current, $\mathrm{J}_{\mathbf{s c}}$.

\section{Higher open-circuit voltages}

A direct method to increase $\mathrm{V}_{\mathrm{oc}}$ is to increase the bandgap of the top cell. The traditional wide-gap alloy has been a-SiC: $\mathrm{H}$ which can be produced with a bandgap of over $2 \mathrm{eV}$. However, until recently the wider-gap material exhibited poor transport properties. Significant improvements in the quality of material and devices is achieved by using large ratios of hydrogen-to-methane gas mixtures for deposition or esoteric carrier gases such as trisilylmethane. ${ }^{16}$ This results in devices having $\mathrm{V}_{\text {oc }}$ over $1.02 \mathrm{~V} .{ }^{16}$ Nevertheless this 
value is less than expected from the values of the Fermi levels in the doped layers and the band tail widths. To date, however, this improvement has not translated into higher efficiency multijunction devices. Increasing the bandgap by alloying silicon with oxygen is receiving increased attention. ${ }^{17}$ So far the $\mathrm{SiO}_{\mathrm{x}}$ alloy is used mainly for the $p$ layer as it gives increased conductivity and better stability. ${ }^{10}$ Changing the growth conditions of the a-Si:H alloy by using hydrogen dilution of the silane and reduced growth temperature produces a wider-bandgap alloy and hence increased $\mathrm{V}_{\mathrm{oc}}{ }^{18}$ This also results in less light-induced degradation. ${ }^{18}$

The optical transmission and activation energy of the $p$ layer along with the $p / i$ interface play an important role in determining $\mathrm{V}_{\mathrm{oc}}$. Because of a fundamental limit to the doping efficiency of amorphous silicon, it is not possible to degenerately dope the material. ${ }^{19,20}$ This difficulty stems from the ease of forming dangling bond defects in the material. Instead of a dopant atom forming a four-fold activated dopant configuration and a free charge, the total energy is lowered by forming charged dangling bond defects and three-fold coordinated dopant atoms. ${ }^{20}$ This results in a square root dependence of the active dopant on the total doping atom density. This limits the activation energy of the amorphous $n$ layer to more than $0.15 \mathrm{eV}$ and of the amorphous $p$ layer to more than about $0.4 \mathrm{eV}$. The larger activation energy for the $\mathrm{p}$ layer is caused by the wider valence band tail. Fortunately, this limitation does not preclude nearly degenerate doping of microcrystalline silicon. For this reason, whenever possible, microcrystalline doped layers are used. While microcrystalline $p$ layers with high transmission and low activation energy offer the potential for high open-circuit voltages, only in device designs in which the $p$ layer is deposited on top of the $i$ layer is the high open-circuit voltage obtained.

Microcrystalline growth on glass, tin oxide, or zinc oxide requires a layer of from $30 . \mathrm{nm}$ to $100 \mathrm{~nm}$ thick of amorphous silicon before a transition to a crystalline phase occurs. ${ }^{13}$ This problem, as yet not overcome, precludes the use of microcrystalline $p$ layers as the bottom doped layer in superstrate structures, because of the requirement that the doped layers must be thin to reduce optical losses. In substrate structures, a microcrystalline $p$ layer can be used as the top contact with significant benefit. Nevertheless, microcrystalline doped layers can be made thin enough to use as $p / n$ recombination-junctions in stacked cells, since they are grown directly on amorphous silicon and not on $\mathrm{ZnO}$ or $\mathrm{SnO}_{2}$.

It is not entirely clear that the lowest activation energy doped layers will produce the highest $\mathrm{V}_{\text {oc }}$. Since the Fermi levels must be continuous across the junction between the doped and amorphous absorber layers, the Fermi level is close to the band edges in the interface transition regions. Since shallow Fermi levels produce charged dangling bond defects, ${ }^{20,}{ }^{21}$ these can have a deleterious effect on recombination and band bending near these interfaces. This may be the reason that $\mathrm{V}_{\mathrm{oc}}$ is never as large as the built-involtage, $\mathrm{V}_{\mathrm{bi}}$ (the difference between the Fermi levels in the doped layers), would predict. ${ }^{22}$ Solar cell simulations show that these charged defects produce voltage losses near the $i / p$ and $i / n$ interfaces that reduce the electric field in the $i$ layer to zero at about $0.3 \mathrm{eV}$ below $\mathrm{V}_{\mathrm{bi}}$. This effect produces an upper limit to $\mathrm{V}_{\mathrm{oc}}$ that is approached in the best devices. ${ }^{22}$

\section{Increased fill factor}

The fill factor is determined mainly by recombination in the $i$ layer. Although there are 
speculations that interfaces play a role in recombination, mid-gap defects distributed throughout the $i$ layer account for most of the recombination under actual operation. Thus, the best route to higher efficiency is to reduce these defects. The main defect acting as a recombination center is the three-fold coordinated silicon dangling bond. In

the as-grown or annealed state these defects are on the order of or below $1 \times 10^{15} \mathrm{~cm}^{-3}$. This density does not compete with the shallower band tail states and is thus not a problem for the initial FF. The problem with the dangling bond is that light- induced degradation typically increases this defect density by up to two orders-of-magnitude where they now become the dominant recombination center and reduce the fill factor to below about 0.60 in the mid-gap cell and even further in the narrow-gap cell of a multijunction structure. Some innovative growth techniques make a material that shows a lower defect density following light-induced degradation. ${ }^{23-26}$ However, these materials have yet to be incorporated into high efficiency devices. As long as the defect density remains high, the traditional method to increase FF is to make the absorber layer thinner. However, this solution is not without the price of reduced optical absorption.

\section{Increased short-circuit current}

Absorption in the $i$ layer determines the short-circuit current. How much light is absorbed depends on the product of the optical absorption coefficient and the $i$ layer thickness. The thickness of the absorber layer is limited by the transport properties in the $i$ layer. Distortion of the electric field and FF reduction due to photogenerated charge limit the thickness to less than $1 \mu \mathrm{m} .{ }^{27}$ Thus, light trapping is the key to high short-circuit current. Present light trapping schemes fall far short of trapping all the light. Increased research, both theoretical and experimental, is important to make improvements in this area.

Reflection and absorption losses in each layer of a multijunction structure can be considerable. The losses can be estimated for each component of a cell using an optical model. $^{28}$ For example in an a-Si:H/a-SiGe:H dual-junction superstrate device with an $\mathrm{SnO}_{2} / \mathrm{Ag}$ back reflector when illuminated by a global AM1.5 spectrum, the current losses are $12 \mathrm{~mA} / \mathrm{cm}^{2}$, leaving only $20.9 \mathrm{~mA} / \mathrm{cm}^{2}$ short-circuit current. ${ }^{28}$ Some improvement might come from increasing the absorption by shrinking the bandgap of the a-SiGe:H component cell. However, these actions usually mean some reduction in transport properties although use of hydrogen dilution of the source gases is a recent method to improve the material. The biggest improvements will come from reducing the air/glass reflection, and the absorption losses in the transparent conductive oxide and the back reflector. These three losses account for over 57\% of the current losses and each contributes roughly the same amount. Considerable effort is being expended to reduce these losses by the use of anti-reflection coating on the glass, improving the properties of the CTO, and designing new back reflectors.

\section{Goals}

The goals adopted for triple-junction devices by component cell are shown in Table 2 . The goals may change if the bandgap distribution is changed. Presently, there are two options for the mid-bandgap component cell, namely, 1.70-1.75 eV a-Si:H or 1.60-1.65 $\mathrm{eV}$ a-SiGe:H. The present status of corresponding parameters for small-area amorphous 
silicon cells is shown in parentheses in Table 2 and is based on cell data from the PV industry after 600 hours light-soaking at $1000 \mathrm{~W} / \mathrm{m}^{2}$ and $50^{\circ} \mathrm{C}$. The mid- and lowbandgap small cells were degraded under illumination with filters, as explained in the footnotes to the table.

Table 2. Long-term amorphous silicon cell stabilized performance goals to meet the $15 \%$ module goal [Guha et al. 19937]

\begin{tabular}{|c|c|c|c|c|c|}
\hline $\begin{array}{l}\text { Component } \\
\text { Cell }\end{array}$ & \begin{tabular}{|l} 
Bandgap \\
$(\mathrm{eV})$
\end{tabular} & $\begin{array}{l}\text { Voc } \\
\text { (V) }\end{array}$ & FF & $\begin{array}{l}\text { Jsc } \\
\left(\mathbf{A} / \mathbf{m}^{2}\right)\end{array}$ & $\begin{array}{l}\text { Power } \\
\left(\mathbf{W} / \mathbf{m}^{2}\right)\end{array}$ \\
\hline $\begin{array}{l}\text { Wide- } \\
\text { Bandgap } \dagger\end{array}$ & $1.9-2.0$ & $\begin{array}{c}1.10 \\
(0.98) \mathrm{d}) \\
(0.97) \mathrm{c})\end{array}$ & \begin{tabular}{|c|}
0.75 \\
$(0.68) \mathrm{d})$ \\
$(0.72) \mathrm{c})$
\end{tabular} & $\begin{array}{l}>82 \\
(80) d) \\
(73) c)\end{array}$ & \begin{tabular}{|l}
68 \\
$(53) d)$ \\
$(50) c)$ \\
\end{tabular} \\
\hline \multirow[t]{2}{*}{$\begin{array}{l}\text { Mid- } \\
\text { Bandgap(a) } \dagger\end{array}$} & $\begin{array}{l}1.70-1.75 \\
\text { a-Si:H }\end{array}$ & $\begin{array}{c}0.95 \\
(0.87) c)\end{array}$ & $\begin{array}{c}0.75 \\
(0.61) c)\end{array}$ & $\begin{array}{l}>84 \\
(62) c)\end{array}$ & $\begin{array}{c}60 \\
(33) c)\end{array}$ \\
\hline & $\begin{array}{l}\text { 1.60-1.65 } \\
\text { a-SiGe:H }\end{array}$ & $\begin{array}{c}0.89 \\
(0.74) c)\end{array}$ & $\begin{array}{c}0.70 \\
(0.60) c)\end{array}$ & $\begin{array}{c}84 \\
(76) c)\end{array}$ & $\begin{array}{c}52 \\
(35) c)\end{array}$ \\
\hline $\begin{array}{l}\text { Low- } \\
\text { Bandgap(b) }\end{array}$ & $1.40-1.45$ & \begin{tabular}{|c}
0.68 \\
$(0.66) \mathrm{c})$ \\
\end{tabular} & \begin{tabular}{|c}
0.68 \\
$(0.55) \mathrm{c})$ \\
\end{tabular} & $\begin{array}{l}>86 \\
(98) \mathrm{c}) \\
\end{array}$ & $\begin{array}{l}>40 \\
(36) \mathrm{c}) \\
\end{array}$ \\
\hline Devices & & $\begin{array}{l}2.60 \\
(2.44) c) \ddagger\end{array}$ & $\begin{array}{l}0.72 \\
(0.61) c) \ddagger\end{array}$ & $\begin{array}{l}>83 \\
(77) c) \ddagger\end{array}$ & $\begin{array}{c}160 \\
(115) c)\end{array}$ \\
\hline
\end{tabular}

(a) umder $\lambda>530 \mathrm{~nm}$ light as seen by the mid-cell in a triple-stack.

(b) under $\lambda>630 \mathrm{~nm}$ light as seen by the bottom-cell in a triple-stack.

(c) United Solar Systems Corporation data.

(d) Solarex Corporation data not on $\mathrm{Cr}$, but with a thick $n$ layer.

$\dagger$ with $\mathrm{Cr}$ reflector for low reflectance. $\ddagger 360$ hours light-soaking

\section{RESEARCH APPROACHES}

Much of the work in designing a-Si devices is a result of trying to compensate for the Staebler-Wronski effect. For example, it was found in the early 1980s that thinner a-Si layers resulted in either less or slower degradation. But cells made thin (i.e., with layers hundreds of nanometers instead of several micrometers thick) allow too much light to pass through unused. To capture more of the light, a-Si devices use one of two strategies or a combination of both: (1) they use a back reflector (such as silver-coated zinc oxide) or (2) they modify the device and make it a multijunction device consisting of many layers having different bandgaps. The latter approach has become the mainstream strategy for both more stable cells and higher efficiencies. Various secondary improvements (new conductive oxides, new back reflectors, microcrystalline silicon doped layers) are also being developed to add to device efficiency. 


\section{Approaches for Reduced Staebler-Wronski Effect}

Light-induced degradation of amorphous silicon has plagued the material since the phenomenon was discovered in $1976^{29}$ and has produced intense interest in metastable changes in a-Si:H. Light, or charge injection, can produce these metastable changes. The main result of these metastable changes is an increase in the density of neutral dangling bond defects, the dominant recombination center. To date, there is no solution to this problem. Although the degradation can be completely removed by annealing the material or device at an elevated temperature, the degradation begins anew and proceeds until annealing balances degradation.

Light-induced degradation under standard operating conditions $\left(1 \mathrm{sun}, 50^{\circ} \mathrm{C}\right)$ has decreased from $\sim 50 \%$ for early (1987) single-junction cells to less than $17 \%$ for multijunction modules now for one year's equivalent exposure to illumination. Triplejunction cells of 10-11\% initial efficiency have shown typical SWE degradation as low as $12 \%$ for one year's equivalent insolation.

The instability issue is intrinsic to amorphous silicon films. The effect is readily observed in films by a decrease in photoconductivity and an increase in mid-gap defects. It is these defects that decrease the cell efficiency. Although many explanations have been proposed, none is universally accepted. The cause is excess energy, such as through electron-hole recombination, near a susceptible site. The exact nature of the susceptible sites and subsequent conversion to a metastable defects is still under discussion.

Two models, namely those proposed first, have survived the test of time, but still are supported only by correlation rather than by proof. One model proposes that a weak Si-Si bond is broken by light, resulting in the observed increase in neutral dangling bonds. This basic model is commonly referred to as the "bond-breaking model" of metastability. Bond-breaking models have received considerable attention. Researchers at Xerox ${ }^{30}$ are strong supporters of a variation of this type of model involving long range hydrogen diffusion. Experimental observations require diffusion of hydrogen after a weak bond is broken by energy from an electron-hole recombination. Alternatively, the energy from an electron-hole recombination may inject hydrogen into a weak silicon-silicon bond, thereby forming a defect. To date, hydrogen diffusion can not be detected as a result of light-induced-degradation. ${ }^{31}$

An alternative model is that charged dangling bonds are present in undoped a-Si:H and they can convert to a metastable neutral dangling bonds by trapping of photogenerated carriers. ${ }^{32,33}$ Charge-trapping models can explain the experimental observations as well as the weak Si-Si bond model. Trapping a charge of the opposite sign on a charged defect along with bond rearrangement can create a neutral dangling bond. ${ }^{32,33}$ There are many sources of charged dangling bonds. They arise from short-range potential fluctuations in the material. The two main sources of potential fluctuations are microvoids and silicon hydrogen bonds. ${ }^{34}$ The density of microvoids (the void fraction) has been steadily reduced over the years with improvement in growth technology. Since there is a correlation between microvoids and instability, ${ }^{35}$ this has resulted in more stable materials. Since hydrogen produces potential fluctuations, reducing its concentration can also result in more stable material.

For high quality a-Si:H films, impurities are not suspected as a cause for degradation. Only for impurity contents well above those found in good quality material, 
has there been a correlation of degradation with impurities.

Following the early speculation ${ }^{36}$ that hydrogen was involved in degradation, there has been a concentrated effort to make material with a lower hydrogen content. This has met with limited success until recently, because lower hydrogen content material usually showed inferior transport properties compared to that containing 10 at.\% hydrogen. Using the hot wire deposition process, device quality a-Si:H can be made with less than 0.1 at.\% hydrogen ${ }^{24,37}$ Investigations of the stability of material made by this technique indicate that it is more stable than material made by glow discharge. Glow discharge produced a-Si:H, containing 10 at.\% hydrogen, typically degrades to a dangling bond density of nearly $1 \times 10^{17} \mathrm{~cm}^{-3}$. Hot-wire-produced material, containing 2-3 at.\% hydrogen, degrades to $2-3 \times 10^{16} \mathrm{~cm}^{-3}$ dangling bonds. ${ }^{38}$ Thus, one hopes that when this material is incorporated into high efficiency devices, degradation will be reduced. Because the lower hydrogen content material is grown at higher temperature (about $360^{\circ} \mathrm{C}$ ) than used for glow discharge, it is not clear whether it is the lower hydrogen content or the higher growth temperature that is responsible for the better stability.

The model of the Staebler-Wronski effect depending on conversion of charged dangling bonds to neutral dangling bonds did not receive much support until recently, because there was no evidence that the charged dangling bonds were present in undoped material. However cogent theoretical reasons for their existence ${ }^{34}$ and recent experimental evidence that they are present ${ }^{39}$ have fostered renewed interest in this model. Experiments on lightly doped $p$-type material have demonstrated that positive charged dangling bonds are converted to metastable neutral dangling bonds when they trap an electron. ${ }^{40,41}$ The reverse reaction of converting neutral to charged dangling bonds by charge trapping is also observed. ${ }^{40,41}$ These observations lend support to the model that charged dangling bonds are responsible for the Staebler-Wronski effect.

\section{Device solutions to instability issue}

For the present, engineering solutions must suffice to reduce the light-induced degradation to manageable levels. Thinner devices have demonstrated improved stability. The higher electric field across a thinner device quickly sweeps out the generated electrons and holes, reducing the probability of recombination which in turn reduces the probability of defect creation. The need for thinner devices for increased stability complements the need for multijunction devices for higher efficiencies. However, these solutions are at the expense of device efficiency, since a thicker device (to some limit) will have increased stabilized efficiency.

\section{Status of alloy research}

For high-efficiency, multijunction cells, both high- and low-bandgap alloys with respect to a-Si:H, are required. The wide-bandgap alloy absorbs the blue portion of the solar spectrum and is used as the front junction. The low-bandgap material is required for absorption of the red portion of the solar spectrum and is usually the back absorber in a multijunction module.

Perhaps the largest improvement in device efficiency will come from improvement of the a-SiGe:H alloys. Research has concentrated on the development of a-SiGe:H alloy 
films with bandgaps near $1.4 \mathrm{eV}$, since this is the bandgap required for achieving the highest efficiency triple-junction module. This alloy is still not as good as those with slightly higher bandgaps. Nevertheless, improvements in material and device quality are constantly being made. ${ }^{14,42}$ Overall, the electrical transport properties of a-SiGe:H may be sufficient for multijunction devices in the range of $14-15 \%$ efficiency. Fundamental improvements in the alloy are required for higher efficiencies. The valence bandtail width in a-SiGe:H alloys is similar to that of a-Si:H, but the conduction bandtail is wider, resulting in a an electron mobility less than for a-Si:H. The electron mobility-lifetimeproduct, derived from photoconductivity measurements, is an order of magnitude lower in a-SiGe alloys $\left(10^{-6} \mathrm{~cm}^{2} / \mathrm{V}\right)$ compared to a-Si:H $\left(10^{-5} \mathrm{~cm}^{2} / \mathrm{V}\right)$. The density of mid-gap defect states is similarly an order of magnitude higher in a-SiGe alloys $\left(10^{16}-10^{17}\right.$ defects $\left./ \mathrm{cm}^{3}\right)$ compared to a-Si:H $\left(10^{15}-10^{16}\right.$ defects $\left./ \mathrm{cm}^{3}\right)$.

Current research efforts include establishing correlations between microstructure and electrical properties; study of different deposition methods to achieve changes in performance; and device designs to overcome inherent limitations in the current alloys. Some of the newer deposition methods, such as, increased ion bombardment, ${ }^{43}$ Hot Wire ${ }^{44}$, and Chemical Annealing using Remote Microwave Plasma $(\mathrm{CA})^{45}$, have produced superior a-SiGe:H alloys.

Significant improvement in a-Si:C:H alloy material has been made using hydrogen dilution of methane. These developments have been incorporated into single-junction solar cells with $\mathrm{V}_{\mathrm{oc}}=1.0 \mathrm{~V}, \mathrm{FF}=0.74$, and $\mathrm{J}_{\mathrm{sc}}=8.4 \mathrm{~mA} / \mathrm{cm}^{2}$ and having remarkable stability. The devices degrade only $13 \%$ after 1700 hours of AM1.5 illumination. ${ }^{18,46}$ If these structures can be incorporated into triple-junction modules, they should help to bring the stabilized efficiency of superstrate modules well above $10 \%$. There is room for significant improvement, since the bandgap of these alloys is $>1.9 \mathrm{eV}$ and $\mathrm{V}_{\text {oc }}$ is nearly half that value. Perhaps some of the innovative deposition techniques that show promise for a-SiGe:H alloys can be equally successful in producing better a-SiC:H.

\section{Computer modeling}

Considerable progress has been made in modeling of solar cells since the early approximate models designed to incorporate only the important physics. ${ }^{27,47,48}$ Now, extensive computer simulations are devised to model multijunction devices. ${ }^{14,49,50}$ These models incorporate most of the important parameters. The main difficulty with all simulations is that they contain a multitude of parameters whose magnitudes are not well defined. One example of this is the mobility. Simulations use the microscopic or free carrier mobility, whereas experiments determine, at best, the trap-limited drift mobility. The connection between these mobilities is tenuous. Another poorly defined quantity is the lifetime. This is usually defined in terms of a capture cross section. However, measurements of the mobility-lifetime-product show that the capture cross section does not change when the mobility changes with temperature. ${ }^{51}$ This behavior implies that the lifetime is inversely proportional to the mobility, an indication of Langevin capture. ${ }^{52}$ This property should be incorporated into the models.

To circumvent the limitations dictated by an incomplete knowledge of the magnitude of the parameters of the model, these magnitudes are chosen or modified to fit a variety of device configurations with the same set of physical (deposition) 
parameters. This gives one confidence that the magnitude of important parameters are chosen correctly. The simulations do explain, after the fact, a great deal about the behavior of complex devices and can give one a great deal of insight into the workings of a complex device and are great aids to device optimization. It is hoped that the values of key parameters will be determined in the future with sufficient accuracy that simulations will become reliable predictors of device efficiency. One model, Analysis of Microelectronic and Photonic Structures (AMPS), is widely used in the U.S. by members of the NREL Amorphous Silicon Teams, partially because of the good results obtained with this model and partially because it is available for use on personal computers. ${ }^{49}$ It will be useful to include the wave optics of textured substrates in the next generation of models.

\section{FUTURE PLANS}

Perhaps the most significant improvements in both device efficiency and stability will come from innovative deposition techniques that improve the transport properties and reduce the defect density. Some techniques that hold promise because they have produced material with lower stabilized defect density are: ECR, ${ }^{22}$ Chemical Annealing using Remote Microwave Plasma (CA) ${ }^{45}$, and Hot Wire. ${ }^{24}$ The first two use electrical discharge to produce the radicals necessary for deposition, while the Hot Wire technique relies on a catalytic decomposition on a hot tungsten wire. All have reported low initial defect density and more stable material, as determined by the increase of defect densities, based on measurements of films. ${ }^{24,45,53}$ However, none has yet produced a high-efficiency device and shown it to be more stable than the standard glow discharge-deposited material. ${ }^{13,} 54$ This situation stems mainly from the fact that many man-years have been spent to develop the expertise to make high-efficiency devices by glow discharge deposition. The newer technologies require significant time and effort to move down the leaming curve. Both ECR and CA produce material at deposition rates lower than for glow discharge whereas Hot Wire produces high quality material at deposition rates as high as $5 \mathrm{~nm} / \mathrm{s} .{ }^{15}$ For an economical process, a high growth rate is necessary, especially as manufacturing plants increase in size. All three methods have also demonstrated superior a-SiGe alloys. ${ }^{42,45}$

A recent approach to a more efficient device is to use a poly- or microcrystalline layer for the low-gap absorber in a multijunction device. The poly- or microcrystalline layer is made by plasma deposition. The microcrystalline layer is made by high frequency glow discharge ${ }^{55}$ and the polycrystalline layer is made by high temperature recrystallization of an amorphous layer ${ }^{56}$ or by hot-wire deposition. ${ }^{57,58}$ To date, these techniques have not produced high efficiency devices, although they hold great promise if they do.

\section{OUTLOOK}

Larger a-Si production is expected within the next few years as two companies (United Solar and APS) start or expand production in their 10-MW/year-capacity a-Si factories. The United Solar plant is based on an advanced multijunction design. The APS plant is presently producing single-junction modules. United Solar has just placed an order for 
equipment to give an additional 5-MW/year production capacity using a sixth generation roll-to-roll deposition technology. The Amoco/Enron Solar $10 \mathrm{MW} / \mathrm{year}$ capacity plant will produce dual-junction modules of 1 to $8 \mathrm{ft}^{2}$ sizes within two years.

It will be important to the a-Si technology that companies can establish improved commercial module efficiencies with their next generation production. The economics of PV systems, and the market competition from traditional PV, require thin-film efficiencies of at least $8 \%$ just to begin a serious market entry. Other thin-film technologies (CIS and CdTe) will be maturing during the next 5 years and adding competition. Therefore, for long-term competitiveness, $12 \%-15 \%$ stabilized efficiency for a-Si will be required. The issue of SWE degradation remains critical. Even today's best a-Si multijunction device designs do not allow stabilized a-Si cells to approach the efficiencies of other materials (11\% stabilized for a-Si, versus $16 \%$ for other thin films). Furthermore, fundamental choices about manufacturing (such as the need for multiple, very thin layers) are being driven by the SWE. Solutions to the SWE problem would change the nature of the a-Si technology and might yet turn out to be absolutely necessary. Nevertheless, the large manufacturing experience base for manufacturing amorphous silicon should help it to keep its present lead in the marketplace for some time.

\section{Cost Reductions}

A potential strategy to reduce the cost for a-Si is a combination of efficiency increase and unit-area cost reduction. By increasing the stable module efficiency to $10 \%$ from the present commercial production efficiency of $5 \%$ and reducing the per-unit-area price by $50 \%$, a-Si will be in the 12 cents $/ \mathrm{kWh}$ (about $\$ 1 / \mathrm{W}_{\mathrm{p}}$ ) cost range. This is illustrated in Figure 3. The graph in Figure 3 is for 30-year levelized electricity costs for fixed flatplate PV systems based on the DOE 5-year plan for photovoltaics ${ }^{61}$. A module price of $\$ 4 / \mathrm{W}_{\mathrm{p}}$ is used in the graph as the present price. This is based on 1995 amorphous silicon module prices for $100-300 \mathrm{~kW}_{\text {ac }}$ systems, although prices as low as $\$ 3 / \mathrm{W}_{\mathrm{p}}$ (1994 dollars) have been quoted. At $50 \mathrm{~W} / \mathrm{m}^{2}$ (for $5 \%$ efficiency) this gives a $\$ 200 / \mathrm{m}^{2}$ module price and a $39 \notin / \mathrm{kWh}$ electricity cost. Increasing the efficiency to $10 \%$ reduces the electricity cost to about $19 \phi / \mathrm{kWh}$ at the same price per square meter. The per-unit-area cost reduction of $50 \%$ is being addressed in the PV Manufacturing Technology (PVMaT) project and would bring the electricity cost to about $12 \varnothing / \mathrm{kWh}$. Between achievement of the efficiency goals for the next 3 years and the cost reductions resulting from the PVMaT project, we thus have a good chance of reaching the intermediate cost goal of $12 \notin / \mathrm{kWh}$ or The graph also shows that an efficiency of $15 \%$ is required to eventually reduce cost to $6 \phi / \mathrm{kWh}$.

The graph in Figure 4 shows the effect of single-plant production capacity on module cost for different module stable efficiencies. The symbols show projected costs by several manufacturers. ${ }^{59}$

\section{Market outlook}

Approximately two thirds of the electricity generated in the U.S. is consumed in commercial, residential, and institutional buildings. To penetrate this market with PV, a 
$\$ 40$ million five-year Building Opportunities in the U.S. for PV (PV:BONUS) program was started in 1992. This program supports the development of building concepts, the creation and testing of products, and the construction of demonstration buildings. Another application area of interest is utility radial line support and area grid support. To explore these applications the Photovoltaics for Utility Photovoltaic Group was formed, consisting of 90 electric utility members, and the PV for Utility Scale Applications project was created. This project allows emerging module technologies to be tested in systems ranging from 200 to $400 \mathrm{~kW}$. Other applications for PV take advantage of the fact that electricity is often needed at remote locations where the utility grid is not near. Such applications include water pumping, cathodic protection, and communications. The potential U.S. market for PV (based on a system price of $\$ 3 / \mathrm{W}$ ) is over $8.4 \mathrm{GW}$, whereof $7 \mathrm{GW}$ is for electric utility applications ${ }^{60}$. This indicates the vast potential PV market, as in 1994 the total world sales of PV was only about $73 \mathrm{MW}$. Finally, there is a large potential market for PV in the developing world: China, India, Africa, and South and Central America.

Another market niche for a-Si is in space applications. Amorphous silicon has a significant advantage over narrow-gap crystalline materials in space applications partially because of its low mass, its low radiation damage, and because its efficiency decreases only marginally with increasing operating temperature. In space a solar array operates at a higher temperature than a terrestrial array does. Thus, the Staebler-Wronski effect is not as much of a problem as in terrestrial operation. This is because the higher operating temperature produces increased annealing of the degradation resulting in a higher stabilized efficiency. However, space applications could only represent a very small (albeit lucrative) market as compared to terrestrial applications.

The share of a-Si in the overall PV market has been shrinking for several years from a high of $39 \%$ in 1988 to $16 \%$ in 1994 . However, with the bringing on-line of several 10-MW/year-capacity plants, the decline should be reversed. The actual and planned construction of several plants of 10-MW/year capacities by the major a-Si PV manufacturers is an indication of their confidence in amorphous silicon's ability to increase its market share.

\section{REFERENCES}

1. Photovoltaic News, Photovoltaic Energy Systems, Inc. Vol. 14, No. 2 (1995).

2. D. E. Carlson and S. Wagner, in Renewable Energy,, edited by T. B. Johansson, H. Kelly, A. K. N. Reddy, and R. H. Williams (Island Press, 1993), p. 403.

3. E. Yablonovitch and G. D. Cody, IEEE Trans. Elec. Dev. ED-29, 300 (1982).

4. T. Sawada, H. Tarui, N. Torada, M. Tanaka, T. Takahama, S. Tsuda, and S. Nakano, in Conf. Record 23rd IEEE Photovoltaics Specialist Conf., IEEE, New York, (1993), 875.

5. T. J. McMahon and M. S. Bennett, in Proceedings of the First World Conference on Photovoltaic Energy Conversion, Hawaii, (1994), to be published. 
6. J. Yang, P. Ross, T. Glatfelter, R. Mohr, G. Hammond, C. Bernotaitis, E. Chen, J. Burdick, M. Hopkins, and S. Guha, in Conf. Record 20th IEEE Photovoltaics Specialist Conf., IEEE, New York (1988), 241.

7. S. Guha, J. Yang, A. Bannerjee, T. Glatfelter, K. Hoffman, and X. Xu, Proceedings 7th International PVSEC Conf., PVSEC-7, Nov. 1993; published in Solar Energy Materials and Solar Cells, Vol. 34, pp. 329-337, (1994)

8. G. D. Cody and T. Tiedje, in Energy and the Environment, edited by B. Abeles, A.J, Jacobson, and P. Sheng (World Scientific, New Jersey, 1992), p. 147.

9. Y. Kuwano, M. Ohnishi, H. Nishiwaka, S. Tuda, T. Fukatsu, K. Enomoto, Y. Nakashimi, and H. Tarui, in Conf. Record 21st IEEE Photovoltaics Specialist Conf., IEEE, New York, (1982), 1338.

10. J. Yang, A. Banerjee, T. Glatfelter, K. Hoffman, X. Xu, and S. Guha, in Proceedings of the First World Conference on Photovoltaic Energy Conversion, Hawaii, (1994), to be published.

11. M. Izu, X. Deng, A. Krisko, K. Whelan, R. Young, H. C. Ovshinsky, K. L. Narasimhan, and S. R. Ovshinsky, in Conf. Record 23rd IEEE Photovoltaics Specialist Conf., IEEE, New York (1993), 919.

12. D. P. Grimmer and K. R. Paulson, in Proceedings of the 4th PVSEC, Sydney, Australia, (1989), 771.

13. W. Luft and Y. S. Tsuo. (1993). Hydrogenated Amorphous Silicon Alloy Deposition Processes, Marcel Dekker.

14. S. Guha, X. Xu, J. Yang, and A. Banerjee, Appl. Phys. Lett. 66, 595 (1995).

15. C. E. Witt, L. O. Herwig, R. L. Mitchell, H. Thomas, R. Sellers, and D. Ruby, in Proceedings of the First World Conference on Photovoltaic Energy Conversion, Hawaii, (1994), to be published.

16. Y. M. Li, in Amorphous Silicon Technology-1993, edited by E. A. Schiff, M. J. Thompson, A. Madun, K. Tanaka, and P. G. LeComber, Mat. Res. Soc. Symp. Proc. Vol. 297, 1993, p. 803.

17. S. Fujikake, H. Ohta, A. Asano, Y. Ichikawa, and H. Sakai, in Conf. Record 23rd IEEE Photovoltaics Specialist Conf., IEEE, New York, (1993), 875.

18. R. Arya, L..Yang, M. Bennett, J. Newton, Y. M. Li, B. Fieselman, L. F. Chen, K. Rajan, G. Wood, C. Poplawaski, and A. Wilczynski, in Conf. Record 23rd IEEE Photovoltaics Specialist Conf., IEEE, New York, (1993), 790.

19. R. A. Street, J. Non. Cryst. Solids 77\&78, 1 (1985).

20. H. M. Branz and R. S. Crandall, Solar Cells 27, 159 (1989).

21. R. S. Crandall and H. M. Branz, in Conf. Record 21st IEEE Photovoltaics Specialist Conf., IEEE, New York, (1990), 1630.

22. E. Schiff, (1994), private communication.

23. A. H. Mahan, B. P. Nelson, S. J. Salamon, and R. S. Crandall, in Amorphous Silicon Technology-1991, edited by A. Madan, M. J. Thompson, P. G. LeComber, Y. Hamakawa, and P. C. Taylor, Mat. Res. Soc. Symp. Proc. Vol. 219, 1991, p. 673.

24. A. H. Mahan, J. Carapella; B. P. Nelson, R. S. Crandall, and I. Balberg, J. Appl. Phys. 69, 6728 (1991). 
25. R. S. Crandall, Y. S. Tsuo, Y. Xu, A. H. Mahan, and D. L. Williamson, Solar Cells 30, 15 (1991).

26. H. Shirai, J. Hanna, and I. Shimizu, in Amorphous Silicon Technology-1991, edited by A. Madan, M. J. Thompson, P. G. LeComber, Y. Hamakawa, and P. C. Taylor, Mat. Res. Soc. Symp. Proc. Vol. 219, 1991, p. 643.

27. R. S. Crandall, J. Appl. Phys. 55, 4418 (1984).

28. S. Wiedman, J. Morris, and L. Yang, in Conf. Record 21st IEEE Photovoltaics Specialist Conf., IEEE, New York, (1990), 1529.

29. D. L. Staebler and C. R. Wronski, Appl. Phys. Lett. 31, 292 (1977).

30. W. B. Jackson, Phys. Rev. B, 41, (1990).

31. H. Branz, (1995), private communication.

32. D. Adler, Solar Cells 9, 133 (1983).

33. H. M. Branz, R. S. Crandall, and M. Silver, in Proceedings of the Amorphous Silicon Materials and Solar Cells, edited by B. L. Stafford, AIP Conference Proceedings 234, 1991, 29.

34. H. M. Branz and M. Silver, Phys. Rev. B, 42, 7420 (1990).

35. S. Guha, J. Yang, S. J. Jones, C. Yan, and D. L. Williamson, Appl. Phys. Lett. 61, 1444 (1992).

36. W. B. Jackson, J. M. Marshall, and M. D. Moyer, Phys. Rev. B, 39, 1164 (1989).

37. R. S. Crandall, in Photovoltaic Advanced Research \& Development Project, edited by R. Noufi, AIP Conference Proceedings, 268, American Institute of Physics, New York, 1992, p. 81.

38. A. H. Mahan and M. Vanecek, in Amorphous Silicon Materials and Solar Cells, edited by B. L. Stafford, AIP Conference Proceedings, 234, American Institute of Physics, New York, 1991, p. 195.

39. H. M. Branz, Phys. Rev. B, 41, 7887 (1990).

40. M. W. Carlen, Y. Xu, and R. S. Crandall, Phys. Rev. B, 51, 2173 (1995).

41. R. S. Crandall and M. W. Carlen, J. Non-Cryst. Solids, to be published, (1995).

42. A. Terakawa, M. Shima, K. Sayama, H. Tarui, H. Nishiwaka, and S. Tsuda, in Amorphous Silicon Technology-1994, edited by E. A. Schiff, M. Hack, A. Madan, M. Powell, and A. Matsuda, Mat. Res. Soc. Symp. Proc. Vol. 336, 1994, p. 487.

43. P. Wickboldt, D. Pang, and W. Paul, in Amorphous Silicon Technology-1994, edited by E. A. Schiff, M. Hack, A. Madan, M. Powell, and A. Matsuda, Mat. Res. Soc. Symp. Proc. Vol. 336, 1994, p. 547.

44. A. H. Mahan and E. Iwaniszcko, (1994), private communication.

45. J.-I. Hanna, A. Kamo, T. Komiya, H. D. Nguyen, I. Shimizu, and H. Kokado, edited by A. Madan, M. J. Thompson, P. C. Taylor, Y. Hamakawa, and P. G. LeComber, Mat. Res. Soc. Symp. Proc. Vol. 149, 11 (1989).

46. Y.-M. Li, F. Jackson, and R. R. Arya, in Conf. Record 23rd IEEE Photovoltaics Specialist Conf., IEEE, New York, (1993), 850.

47. R. S. Crandall, RCA Review, 42, (1981).

48. $\quad$ R. S. Crandall, J. Appl. Phys. 54, 7178 (1983).

49. F. A. Rubinelli, S. J. Fonash, and J. K. Arch, in Proceedings of the Sixth International PVSEC, (1992), 881.

50. J. C. Kim, R. J. Schwartz, and J. L. Gray, in Conf. Record 23rd IEEE Photovoltaics Specialist Conf., IEEE, New York, (1993), 1001. 
51. H. Antoniadis and E. A. Schiff, Physical Review B - Condensed Matter, 46, 9482 (1992).

52. R. S. Crandall, Phys. Rev. 138, 1242 (1965).

53. V. L. Dalal, E. X. Ping, S. Kaushal, M. Leonard, M. K. Bhan, and K. Han, in Amorphous Silicon Technology-1994, edited by E. A. Schiff, M. Hack, A. Madan, M. Powell, and A. Matsuda, Mat. Res. Soc. Symp. Proc. Vol. 336, 1994, p. 335.

54. - B. P. Nelson, E. Iwaniczko, R. I. Schropp, A. H. Mahan, E. C. Molenbroek, S. Salamon, and R. S. Crandall, in Proceedings of the 12th European PV Solar Energy Conference, Amsterdam, Netherlands, (1994), 679.

55. R. Fluckiger, J. Meier, H. Keppner, M. Goetz, and A. Shah, in Conf. Record 23rd IEEE Photovoltaics Specialist Conf., IEEE, New York, (1993), 875.

56. T. Baba, T. Matsuyama, T. Sawada, T. Takahama, K. Wakisaki, and T. Tsuda, in Microcrystalline and Nanocrystalline Semiconductors, Mat. Res. Soc. Symp. Proc. Vol. 358, 1995, pp. 895-901.

57. H. Matsumura, Y. Hosada, and S. Furakawa, in Amorphous Silicon Technology1994, edited by E. A. Schiff, M. Hack, A. Madan, M. Powell, and A. Matsuda, Mat. Res. Soc. Symp. Proc. Vol. 336, (1994), p. 37.

58. J. Cifre, J. Bertomeu, J. Puigdollers, M. C. Polo, J. Andreu, and A. Loret, Appl. Phys. A, 59, 645 (1994).

59. W. Luft, B. Stafford, and B. von Roedern, in Photovoltaic Advanced Research \& Development Project, edited by R. Noufi (AIP Conference Proceedings No. 268 (American Institute of Physics, New York, 1992), p. 347.

60. Utility Photovoltaics Group, Phase 1 final report, Photovoltaics: On the verge of commercialization, June 1994.

61. U.S. DOE, National Photovoltaics Program Five-Year Research Plan, 1987-1991, p. 30 . 


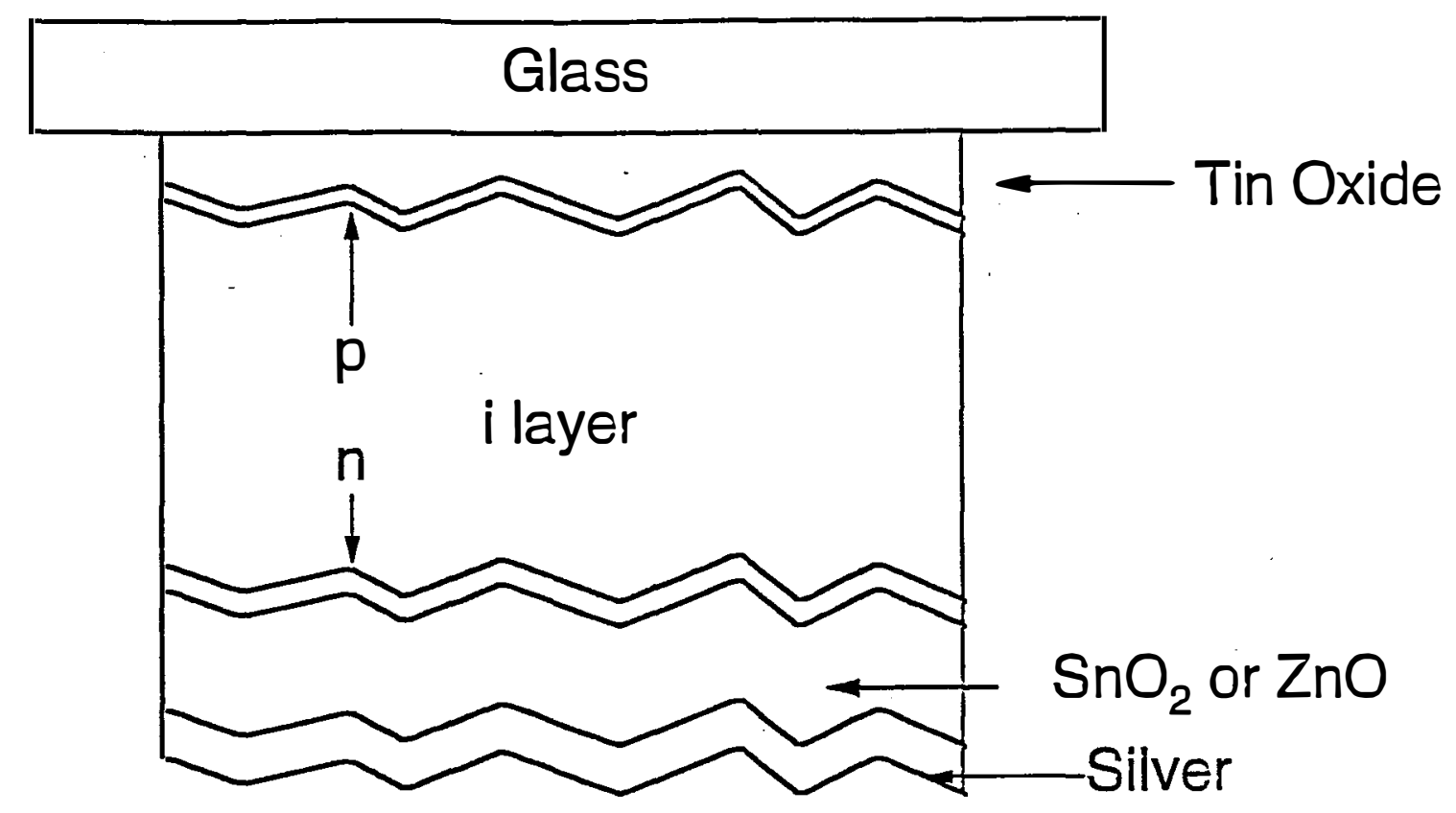

(a)

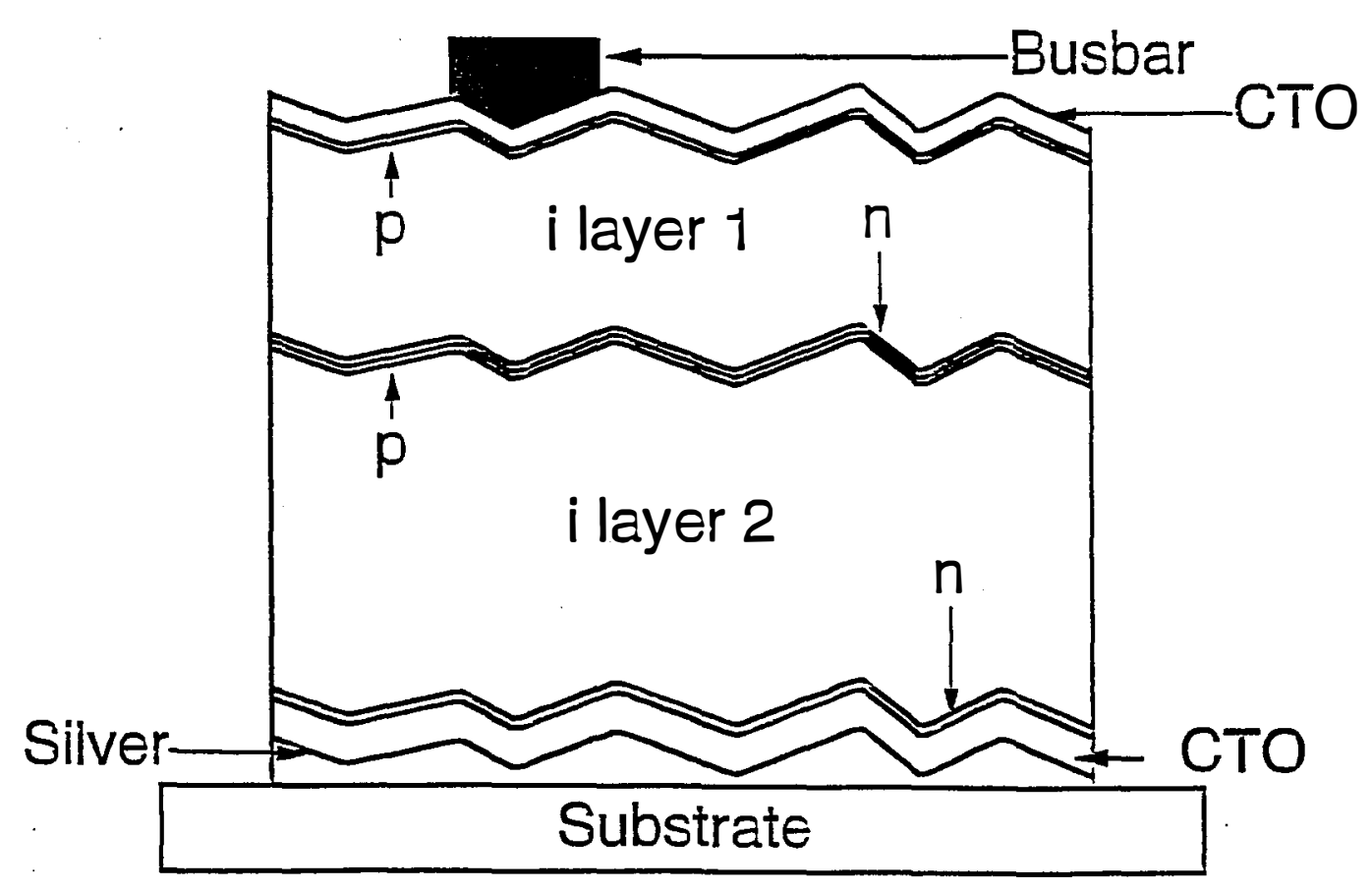

(b)

Figure 1. Schematic cross section of (a) a single-junction p-i-n superstrate structure and (b) a double-junction substrate $n-i-p$ structure. The light enters the top p-layer in both cases. 
Tauc

Bandgap

(eV)
Material Deposition

Process
Thickness

(nm)

$1.5-2.1 \mathrm{~mm}$

$500-800$

10

$60-80$

10

10

$300-450$

10

$160-190$

$10-50$

$80-100$

Figure 2. Typical triple-junction a-Si cell structure. 


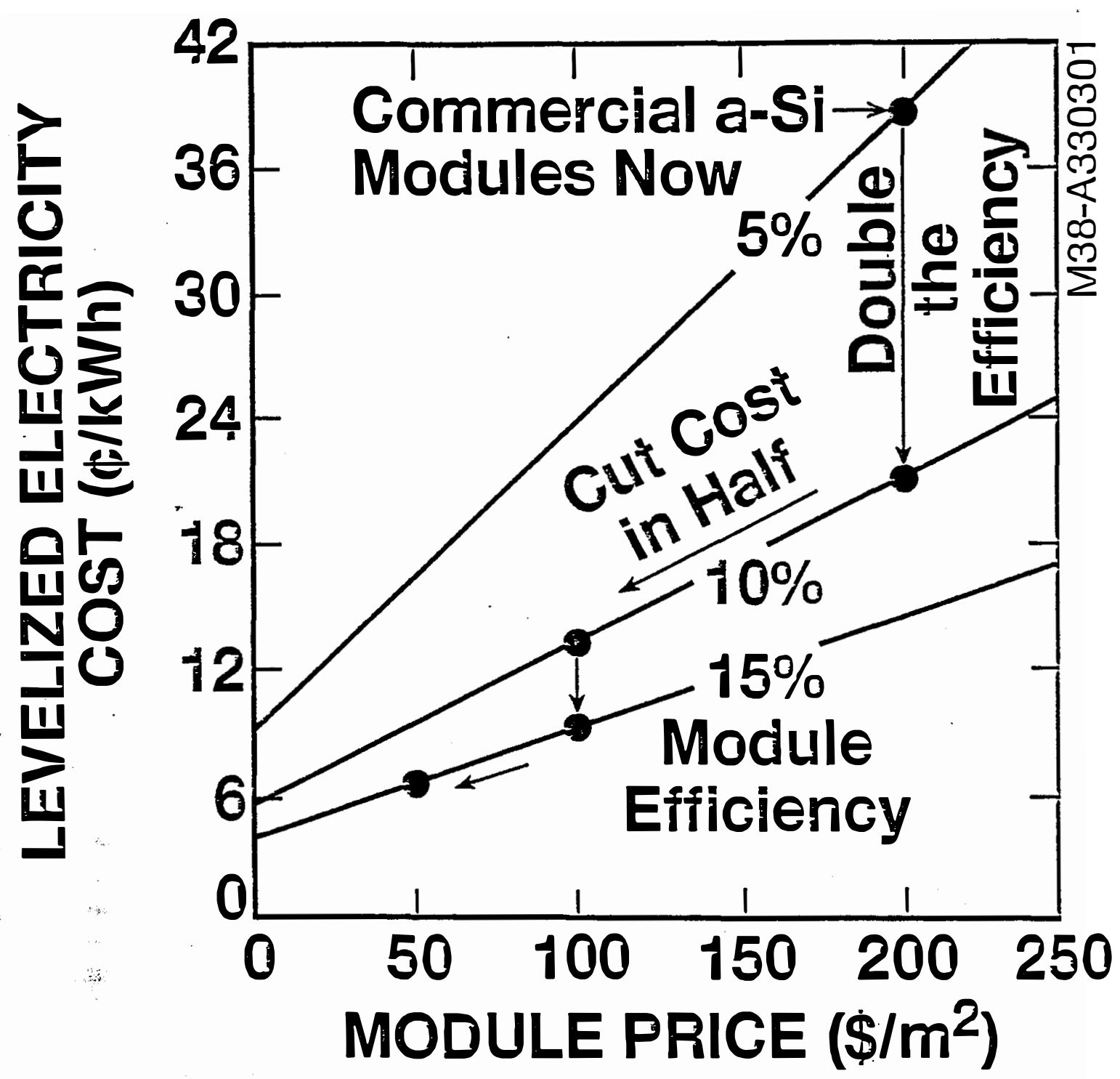

Figure 3. Strategy for a-Si module price reductions [based on Ref. 61]. 


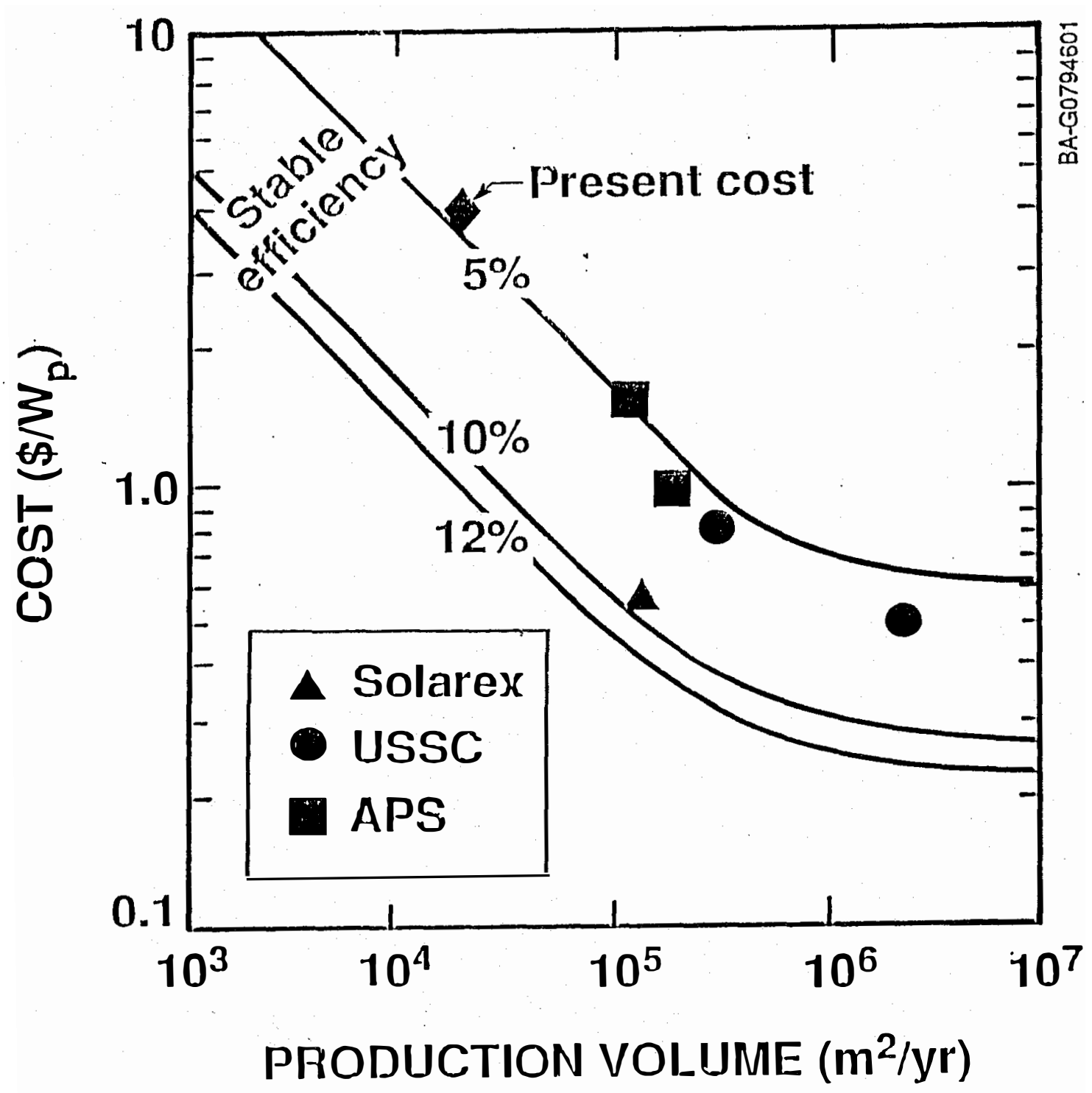

Figure 4. Projected impact of production volume on a-Si modules costs. 